University of Nebraska - Lincoln

DigitalCommons@University of Nebraska - Lincoln

Faculty Publications from the Harold W. Manter Laboratory of Parasitology

$5-1993$

\title{
The Phylogenetic Component of Cooperative Breeding in Perching Birds: A Commentary
}

Deborah A. McLennan

University of Toronto

Daniel R. Brooks

University of Toronto,dnlbrooks@gmail.com

Follow this and additional works at: https://digitalcommons.unl.edu/parasitologyfacpubs

Part of the Parasitology Commons

McLennan, Deborah A. and Brooks, Daniel R., "The Phylogenetic Component of Cooperative Breeding in Perching Birds: A Commentary" (1993). Faculty Publications from the Harold W. Manter Laboratory of Parasitology. 253.

https://digitalcommons.unl.edu/parasitologyfacpubs/253

This Article is brought to you for free and open access by the Parasitology, Harold W. Manter Laboratory of at DigitalCommons@University of Nebraska - Lincoln. It has been accepted for inclusion in Faculty Publications from the Harold W. Manter Laboratory of Parasitology by an authorized administrator of DigitalCommons@University of Nebraska - Lincoln. 


\section{NOTES AND COMMENTS}

\section{THE PHYLOGENETIC COMPONENT OF COOPERATIVE BREEDING IN PERCHING BIRDS: A COMMENTARY}

The study of behavioral and ecological evolution within a phylogenetic context (historical ecology; Brooks and McLennan 1991) is an important component of comparative studies in evolutionary biology. Although the number of historical ecological studies is growing rapidly, this research field is still in its infancy-an infancy whose maturation is hampered by the absence of rigorous phylogenetic hypotheses for many of the groups that have traditionally fascinated behavioral ecologists. In the absence of such critical information, behavioral ecologists are faced with the options either of forming cooperative groups with phylogenetic systematists or of investigating their ecological data based on "trees" reconstructed from old classification schemes or phenograms, neither of which produces a robust phylogenetic hypothesis of genealogy. Most researchers have opted for the second approach, prefacing their investigations with the caveat that the analysis and conclusions are only preliminary because of the unsatisfactory nature of the phylogenetic hypotheses available to them. The importance of a preliminary analysis cannot be underestimated for researchers who, recognizing the importance of incorporating phylogenetic information into evolutionary explanations, are frustrated by their inability to apply such an approach to their burgeoning data sets. It is, however, equally important to realize that a preliminary analysis can, at best, produce only tentative results (see, e.g., Sillen-Tullberg 1988). If the data themselves are both incomplete and ambiguous, this will compound the problems arising from an absence of a rigorous phylogenetic framework, which will produce a confusing picture of behavioral or ecological evolution.

The article by Edwards and Naeem (1993) illustrates both aspects of a preliminary analysis and so is a valuable template for future research. Our intent here is not to critique their study exhaustively but to discuss briefly some methodological strengths and weaknesses of their study, recalling that the weaknesses are symptomatic of a fledgling (and enthusiastic) discipline and thus widespread throughout the literature.

A phylogenetic analysis begins with the assumption that all characters that conform to nonphylogenetic criteria for homology, such as those proposed by Remane (1956), are, in fact, evolutionarily homologous. In some cases this will 
lead to the incorrect, and initially undetected, identification of homoplasious traits as homologues. When a phylogeny is reconstructed by grouping taxa according to their shared homologies, these misidentifications will be revealed because the homoplasious characters will not co-vary with the majority of the other characters. These traits can then be recognized, using the phylogenetic hypothesis, as homoplasies. For a behavioral trait, we might say that if character $a$ looks the same in different species (is performed the same way), then it is the same. This hypothesis of homology is then tested against hypotheses of homology for different characters; the subsequent phylogenetic tree tells us whether our initial assumptions were correct. Although behavioral ecologists are not generally involved with the reconstruction of phylogenetic trees, they are still subject to the same set of criteria when attempting to interpret their data within a phylogenetic context: begin with the assumption that different traits that look the same in different species are the same, then optimize those characters onto a phylogenetic tree to test that assumption. Edwards and Naeem (1993) begin their study with the assumption that cooperative breeding "means 'a system of breeding that is characterized by the normal presence of helpers at some or all nests' . . . where a helper is 'an individual that performs parent-like behavior toward young that are not genetically its own offspring', (Brown 1987, p. 6, cited in Edwards and Naeem 1993). At this point, it appears that cooperative breeding can be hypothesized to be the "same" trait. However, later in the article, the authors explain that all cooperative breeding systems are, in fact, not the same; "cooperative breeding," for example, can include both male and female helpers or male helpers only, and it can occur within a monogamous or polygynandrous mating system. This indicates that we must begin with the hypothesis that "cooperative breeding" as a character is nonhomologous in the species that display it; in other words, we are dealing with a character class, not with a character.

The confusion of a behavioral character class with the character itself is not an uncommon one in the literature. In fact, evolutionary biologists have often asked questions about the evolution of character classes like territoriality, monogamy, or parasitism. The use of a phylogenetic approach requires us to define our characters more rigorously. This rigor is particularly important if we are to ask questions about adaptation because the strongest test for adaptation is the convergent appearance of the same trait in the same environmental context (see Brooks and McLennan 1991 and references therein). For example, Edwards and Naeem (1993) have uncovered the convergent appearance of cooperative breeding both within (Campylorhynchus) and among clades of passerine species. The next question that must be asked is whether these putative convergences are the same or different characters. If further investigation reveals that "cooperative breeding", is different in different groups, then there is no a priori reason to expect to find ecological correlates for its evolution. In fact, if "cooperative breeding" is really a class of several different characters and the different types of cooperative breeding represent the outcome of a finely tuned interaction between the organism and its environment, then we would expect to find no correlation between the evolution of "cooperative breeding" (the character class) and specific ecological conditions. Under the assumption of homology, this result looks chaotic and can only 


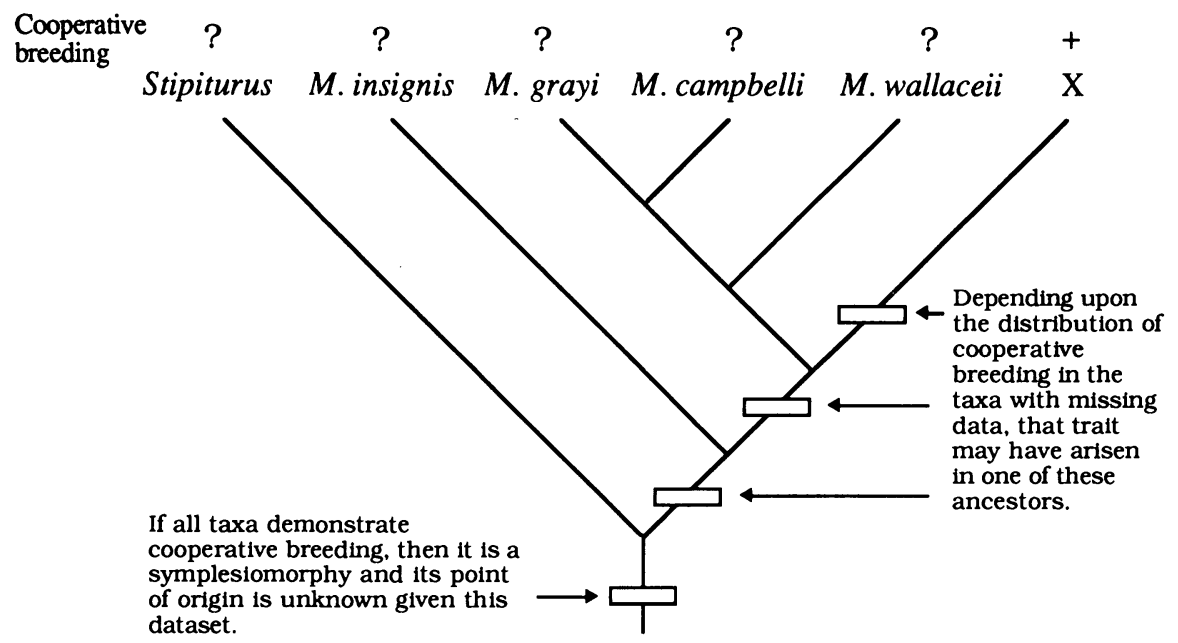

FIG. 1.-Available information about the presence or absence of cooperative breeding is mapped above the tentative phylogeny for the fairy wrens (Malurus) and their closest relatives. A question mark indicates missing data; $X$ denotes the clade composed of $M$. cyaneus, $M$. splendens, $M$. amabilis, $M$. lamberti, M. pulcherrimus, $M$. elegans, $M$. coronatus, $M$. cyanocephalus, $M$. alboscapulatus, $M$. melanocephalus, and $M$. leucopterus. If cooperative breeding is only found in group $X$, then it originated within the genus Malurus. If, on the other hand, cooperative breeding is found in all of these taxa, then it is a symplesiomorphy and we need information from additional outgroups in order to pinpoint its origin.

be interpreted to mean that the environmental factors under examination were not causally involved in the success of cooperative breeding once it appeared. However, if the category "cooperative breeding" is actually several different characters like "male only helpers in a monogamous system" or "male and female helpers in a polygynandrous system," then Edwards and Naeem may have missed some interesting correlations.

Problems with the definition of "cooperative breeding" notwithstanding, only one of the three clades that Edwards and Naeem examined for possible correlations among ecological characters and the origin of cooperative breeding was informative. Among the fairy wrens, cooperative breeding is known from 11 species forming a monophyletic group. The state of that character is unknown for the sister group, comprised of Malurus wallaceii, Malurus campbelli, and Malurus grayi, so it is impossible to determine whether cooperative breeding arose in the ancestor of the 11-species clade within the genus Malurus or whether it is plesiomorphic for the genus (fig. 1). We cannot resolve this question without having information about the breeding systems in the outgroups. Edwards and Naeem indicate that cooperative breeding may be present in $M$. wallaceii, $M$. campbelli, and $M$. grayi, as well as in related species of emu wrens (Stipiturus). If this is the case, then optimization (Farris 1970; Maddison et al. 1984) of cooperative breeding onto the phylogenetic tree will indicate that this behavior is plesiomorphic for Malurus and Stipiturus. Given that the origin of the trait under investigation is unknown, a search for the potential environmental correlates of that 
origin is not productive at this time. Similar objections apply to the example using Australo-Papuan babblers, in which the presence of cooperative breeding is also plesiomorphic for the group.

The data for the Australian robins are more amenable to phylogenetic analysis. The "tree" presented by Edwards and Naeem supports the hypothesis that cooperative breeding arose in the ancestor of the Eopsaltria australis + Eopsaltria georgiana + Eopsaltria flaviventris + Eopsaltria griseogularis clade and was subsequently lost in E. flaviventris. Outgroup comparisons demonstrate that the absence of seasonality is plesiomorphic for Eopsaltria. If we score the presence of this derived character in the polymorphic species $E$. australis with a + , then it appears that seasonality originated in the same ancestor as cooperative breeding. The hypothesis that the two are causally related in these birds is further strengthened by the observation that seasonality was lost in E. flaviventris (fig. $2 a$ ). Assuming that the sister group relationships of E. flaviventris + E. griseogularis are maintained in a phylogenetic analysis, then resolution of the trichotomy in this clade will not change the hypothesis that cooperative breeding and seasonality may be causally involved. Either the origin/loss scenario described above will be corroborated (fig. $2 b$ and $2 c$ ), or it will be modified to show the convergent origin of cooperative breeding and seasonality (fig. $2 d$ ). Both provide stronger evidence for the relationship between the two variables than a single origin hypothesis (Coddington 1988). This is an interesting discovery. What is required now are experimental investigations of the macroevolutionary hypothesis.

Although Edwards and Naeem do not have enough information to draw any conclusions, tentative or otherwise, about the potential ecological correlates of the evolution of cooperative breeding, they do make a number of valuable points. For example, they have demonstrated that cooperative breeding, once it appears, can persist in a lineage despite changes in that lineage's ecological background. This is consistent with other observations of phylogenetic conservatism in adaptations (see, e.g., Carothers 1984; see discussion and further references in Brooks and McLennan 1991). This discovery and Edwards and Naeem's subsequent discussion of phylogenetic inertia in life-history traits draw together information from a wide variety of sources in an attempt to uncover the causes of such inertia.

The article by Edwards and Naeem is an important contribution because it represents the interface between macroevolutionary and microevolutionary analysis. For example, once we have collected data concerning the environmental and social components of fitness for a particular behavioral system, we can optimize those components onto a phylogenetic tree and ask the following questions: Are there any macroevolutionary correlations between the appearance of the behavioral system and a change in one or more of the components? Which components appear to have been evolutionarily fixed throughout the history of the clade, and which are highly variable? How many components can change and still maintain the system? The results of such analyses will provide a more robust estimate for the relative roles of both phylogenetic factors and environmental factors in the evolution of behavioral systems (Brooks and McLennan 1991). This, in turn, will allow us to formulate more concise hypotheses and predictions based on those hypotheses, which can then be examined experimentally (McLennan 1991). 


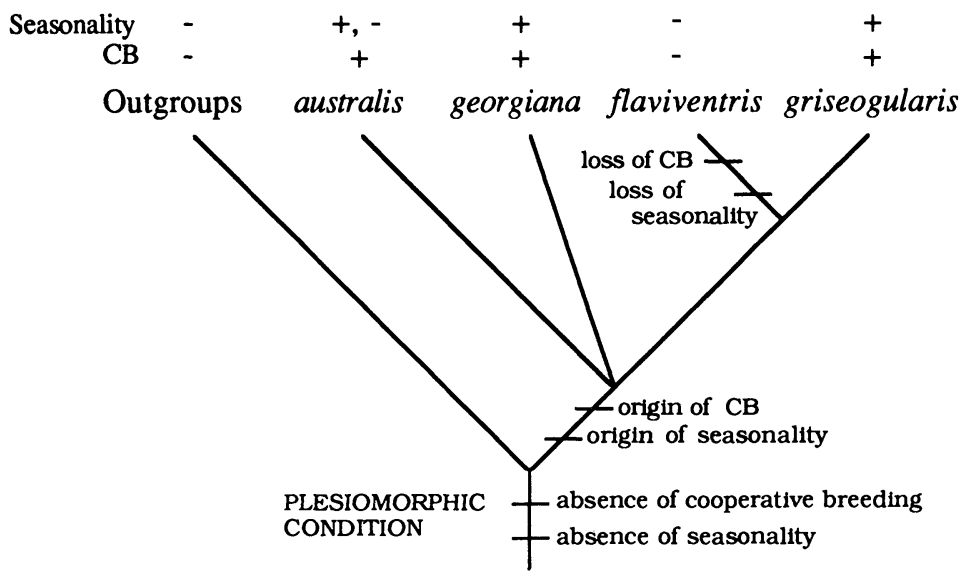

(a)

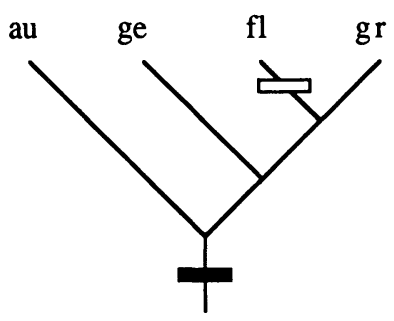

(b)

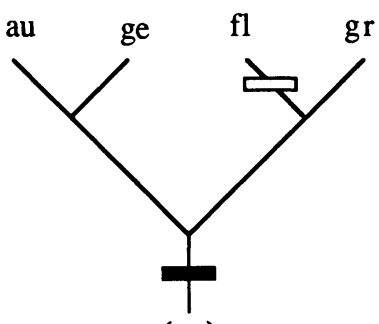

( c )

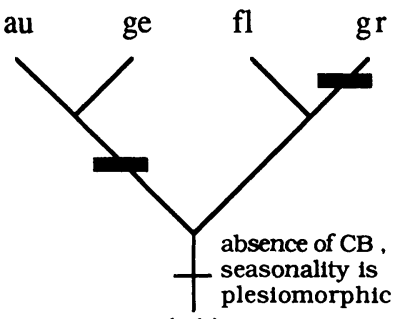

(d)

FIG. 2.-Possible correlations between the evolution of cooperative breeding and the evolution of seasonality in Australian robins (Eopsaltria). a, Optimization of the two characters on the current phylogenetic hypothesis. $b$, Optimization of the two characters onto a hypothetical resolution of the polytomy placing $E$. georgiana as the sister group of $E$. flaviventris $+E$. griseogularis. $c$ and $d$, Two equally parsimonious optimizations of the characters onto a hypothetical resolution of the polytomy placing $E$. georgiana as the sister group of $E$. australis. Solid bars, origin of both cooperative breeding and seasonality; open bars, loss of both cooperative breeding and seasonality; au, E. australis; ge, E. georgiana; $f$, E. flaviventris; gr, E. griseogularis.

\section{ACKNOWLEDGMENTS}

We express our thanks to M. D. Rausher, editor of the American Naturalist, for inviting us to contribute this commentary. Funds for this study were provided by operating grant A7696 from the Natural Sciences and Engineering Council (NSERC) of Canada to D.R.B.

Brooks, D. R., and D. A. McLennan. 1991. Phylogeny, ecology and behavior: a research program in comparative biology. University of Chicago Press, Chicago. 
Brown, J. L. 1987. Helping and communal breeding in birds: ecology and evolution. Princeton University Press, Princeton, N.J.

Carothers, J. H. 1984. Sexual selection and sexual dimorphism in some herbivorous lizards. American Naturalist 124:244-254.

Coddington, J. A. 1988. Cladistic tests of adaptational hypotheses. Cladistics 4:3-22.

Edwards, S. V., and S. Naeem. 1993. The phylogenetic component of cooperative breeding in perching birds. American Naturalist 141:754-789.

Farris, J. S. 1970. Methods for computing Wagner trees. Systematic Zoology 19:83-92.

Maddison, W. P., M. J. Donoghue, and D. R. Maddison. 1984. Outgroup analysis and parsimony. Systematic Zoology 33:83-103.

McLennan, D. A. 1991. Phylogeny and behavior: from pattern to process. Evolution 45:1773-1789.

Remane, A. 1956. Die Grundlagen des naturlichen System der vergleichenden Anatomie und Phylogenetik. 2d ed. Geest \& Protig, Leipzig.

Sillen-Tullberg, B. 1988. Evolution of gregariousness in aposematic butterfly larvae: a phylogenetic analysis. Evolution 42:293-305.

Deborah A. McLennan

DANIEL R. BRoOKS

\section{Department of Zoology \\ UNIVERSITY OF TORONTO \\ Toronto, Ontario M5S i Ai \\ CANADA}

Submitted January 3, 1992; Revised June 10, 1992; Accepted June 16, 1992 